\title{
Attention in schizophrenia and in epileptic psychosis
}

\author{
I.C.J. Kairalla ${ }^{1}$, P.E.L. Mattos ${ }^{2}$, M.Q. Hoexter ${ }^{1}$, R.A. Bressan ${ }^{1}$, J.J. Mari ${ }^{1}$ and \\ I. Shirakawa ${ }^{1}$ \\ ${ }^{1}$ Departamento de Psiquiatria, Escola Paulista de Medicina, Universidade Federal de São Paulo, \\ São Paulo, SP, Brasil \\ ${ }^{2}$ Instituto de Psiquiatria, Universidade Federal do Rio de Janeiro, Rio de Janeiro, RJ, Brasil \\ Correspondence to: I.C.J. Kairalla, Rua Heitor Peixoto, 325/133, 01543-000 São Paulo, SP, Brasil \\ Fax: +55-11-5579-7693. E-mail: ivettek@osite.com.br
}

\begin{abstract}
The adaptive behavior of human beings is usually supported by rapid monitoring of outstanding events in the environment. Some investigators have suggested that a primary attention deficit might trigger symptoms of schizophrenia. In addition, researchers have long discussed the relationship between schizophrenia and the schizophrenia-like psychosis of epilepsy (SLPE). On the basis of these considerations, the objective of the present study was to investigate attention performance of patients with both disorders. Patient age was 18 to 60 years, and all patients had received formal schooling for at least four years. Patients were excluded if they had any systemic disease with neurologic or psychiatric comorbidity, or a history of brain surgery. The computerassisted TAVIS-2R test was applied to all patients and to a control group to evaluate and discriminate between selective, alternating and sustained attention. The TAVIS-2R test is divided into three parts: one for selective attention ( $5 \mathrm{~min})$, the second for alternating attention (5 $\mathrm{min}$ ), and the third for the evaluation of vigilance or sustained attention (10 min). The same computer software was used for statistical analysis of reaction time, omission errors, and commission errors. The sample consisted of 36 patients with schizophrenia, 28 with interictal SLPE, and 47 healthy controls. The results of the selective attention tests for both patient groups were significantly lower than that for controls. The patients with schizophrenia and SLPE performed differently in the alternating and sustained attention tests: patients with SLPE had alternating attention deficits, whereas patients with schizophrenia showed deficits in sustained attention. These quantitative results confirmed the qualitative clinical observations for both patient groups, that is, that patients with schizophrenia had difficulties in focusing attention, whereas those with epilepsy showed perseveration in attention focus.
\end{abstract}

Key words: Attention; Schizophrenia; Psychotic disorders; Epilepsy; Neuropsychology

Research supported by FAPESP (No. 1998/04099-0). J.J. Mari is the recipient of a CNPq IB productivity fellowship.

Received February 22, 2007. Accepted September 21, 2007

\section{INTRODUCTION}

Human beings are exposed to different types of stimuli that must be detected and selected for later processing and for the generation of responses. Therefore, individuals must pay careful attention to the environment, as well as to internal physical and psychological stimuli. Attention is associated with alertness because certain situations require immediate and accurate responses. Several researchers have suggested that attention underlies all other cognitive functions (1-3). An excessive amount of information, which results from dispersive attention, makes it impossible or difficult to understand facts or to identify what is relevant. Also, prolonged focus on one fact rather than on others may lead to distorted conclusions or loss of useful and interesting opportunities.

Lezak (2) referred to attention as a set of several capabilities or different processes that are associated with how the human organism becomes receptive to stimuli and how it processes and responds to either internal or external stimuli. According to that study, four types of attention were defined: a) selective attention: the capacity to select one stimulus, either external or internal, from among several others (including the absence of stimuli). It is the capacity to focus on one or two stimuli or ideas while 
suppressing other stimuli that competitively disperse attention; b) sustained attention (or vigilance): the capacity to keep the focus of attention for a period of time. It refers to readiness and to the ability to detect the next input signal, which may not occur for a long period of time (4); c) divided attention: the ability to respond to more than one stimulus at the same time, or to multiple elements or operations within one activity, such as a complex mental activity; d) alternating attention: the capacity to respond to repeated changes in focus.

Butler and Braff (5) suggested that a primary attention deficit might trigger symptoms of schizophrenia, such as paranoid-type delusions, which may be understood as inadequate attempts to integrate abnormal experiences. The adaptive behavior of human beings is usually supported by rapid monitoring of outstanding events in the environment, which include threatening stimuli. Patients with persecutory delusions, however, show a marked bias towards detecting stimuli associated with threats and towards recalling threatening episodes $(6,7)$. Excessive attention is directed at threatening stimuli when the individual is experiencing delusions, but not after recovery (8). When stimuli in the form of photographs of neutral, threatening or ambiguous social scenes were presented to patients with schizophrenia and persecutory delusion, they rapidly identified the threatening stimuli on the photographs. When photographs with ambiguous scenes were used, patients with schizophrenia and persecutory delusions took less time to identify threatening scenes than patients with schizophrenia and non-persecutory delusions or healthy individuals (9). The slower response of patients with schizophrenia may be associated with a decrease in alertness.

In 1963, Slater et al. (10) reviewed a number of cases that became landmarks in the studies of psychoses in patients with epilepsy. In 1968, Reynolds (11) conducted an analysis of clinical aspects and referred to the three most important hypotheses found in the literature: 1) that the two disorders are biologically antagonistic; 2) that they have a biological affinity, or 3) that any association between the two is completely fortuitous. In 1991, Toone (12) summarized some generally accepted characteristics of what has been called schizophrenia-like psychosis of epilepsy (SLPE). In the literature, SLPE is described as chronic and/or recurrent interictal psychotic episodes of a schizophreniform type with delusions, hallucinations, thought disorder, disorganized behavior, relative absence of catatonic symptoms, mood swings, avolition, affective flattening (less intense than in schizophrenia), persistence of psychotic symptoms, suicide attempts, multiple hospitalizations, and generalized impaired functioning (13).
These two diseases have different prevalence rates: schizophrenia affects about $1 \%$ of the general population, whereas the rate of epileptic psychoses ranges from 3 to $7.1 \%(13)$.

Several investigators have studied attention and attention performance in either schizophrenia or epilepsy, but few have focused on the comparison of these two diseases. Mellers et al. (14) studied the neuropsychological profiles of schizophrenia and SLPE in comparison with healthy controls, and their results will be presented in the discussion of our results.

The purpose of the present study was to investigate the selective, sustained and alternating attention performance of patients with schizophrenia and patients with SLPE compared to healthy control subjects. Our initial hypothesis was that the attentional capacity of patients with schizophrenia would be similar to that of patients with SLPE.

\section{PATIENTS AND METHODS}

Patients included in the study had a confirmed diagnosis of schizophrenia or of partial or generalized epilepsy associated with interictal SLPE for longer than six months; all patients were stable at the time of inclusion. Patient age was 18 to 60 years, and all patients had received formal schooling for at least four years. Patients were excluded if they had any systemic disease with neurologic or psychiatric comorbidity, or a history of brain surgery. Healthy control subjects were 18 to 60 years old, had at least four years of schooling and did not have a history of psychiatric disorders or organic or systemic diseases.

Schizophrenia was diagnosed according to the criteria established in the Diagnostic and Statistical Manual of Mental Disorders, 4th edition (DSM-IV) (15). The diagnosis of schizophrenia was confirmed by the presentation of 36 vignettes to two independent psychiatrists experienced in the treatment of schizophrenia. Epilepsy was diagnosed according to the criteria established in the Classification of Epileptic Seizures (16), and the Classification of Epilepsies and Epileptic Syndromes (17) of the Commission on Classification and Terminology of the International League Against Epilepsy. Interictal SLPE was diagnosed according to the Pond Classification (18). All the healthy controls underwent psychiatric evaluation conducted by one of the authors to exclude a history of psychiatric symptoms according to the criteria established in the DSM-IV.

The research protocol was approved by the Research Ethics Committee of Universidade Federal de São Paulo (EPM, UNIFESP) and written informed consent was obtained from all participants.

Patients with schizophrenia were recruited in the out- 
patient service of the Schizophrenia Program of the Department of Psychiatry of the Universidade Federal de São Paulo (UNIFESP), São Paulo, SP, Brazil. Patients with epilepsy were recruited at two services: a) the outpatient clinic of the Service of Investigation and Treatment of Epilepsies of the Neurology and Neurosurgery Department of UNIFESP, and b) the outpatient service of the Epilepsy and Psychiatry Project (PROJEPSI) of the Institute of Psychiatry at Hospital de Clínicas, School of Medicine, Universidade de São Paulo, São Paulo, SP, Brazil. Healthy controls were selected from two groups of volunteers: firefighters of different ranks from the Fire Department of São Paulo, and parents of students in a São Paulo school. Firefighters were examined when not on duty call, when their attention was not particularly increased by their work.

All participants took the computer-assisted TAVIS-2R test to evaluate attention (19) and the Raven's Progressive Matrices test (20) to assess intelligence.

The computer-assisted TAVIS-2R test is divided into three parts: one for selective attention ( $5 \mathrm{~min}$ ), the second for alternating attention ( $5 \mathrm{~min}$ ), and the third for the evaluation of vigilance or sustained attention (10 min). In this test, all symbols are familiar: tic-tac-toe symbols in task 1 (selective attention); colors and basic geometric shapes in task 2 (alternating attention), and a small solid circle in task 3 (sustained attention). In task 1 , geometric shapes successively appear one by one at 1-s intervals and remain on the screen until the screen is full. The test-taker should press a joystick button each time the shape previously agreed upon with the examiner appears on the screen. In task 2, pairs of geometric shapes (squares, triangles or circles in yellow, red or blue) appear on the screen at random and the test-taker receives alternate orders to press the button when either a pair of equal shapes or a pair of equal colors appears on the screen. In task 3 , the screen is black for $10 \mathrm{~min}$, and the test-taker is told to press the button only when a small solid red circle appears on the screen, which happens sporadically and unpredictably on different parts of the screen. The same computer software was used for statistical analysis of reaction time, omission errors and commission errors.

The Raven test evaluates the capacity to establish adequate strategies to solve problems according to an essentially visual (nonverbal) pattern of functioning. Test results are not affected by the patient's educational background and do not include verbal aspects that may lead to translation distortions or biases secondary to vocabulary, which is dependent on socioeconomic status. This test is widely used to evaluate intelligence $(21,22)$ and is the standard tool used to validate associated tests.
The following questionnaire was applied for the evaluation of all healthy controls. 1) Have you ever received treatment for any mental disorder? 2) Have you experienced or are you currently experiencing moments of psychological tension that have compromised or interrupted your daily life activities? 3) Do you have any difficulty to pay attention to or focus attention on what you are doing? 4) Do you have any memory problems? 5) Healthy controls also answered questions evaluating symptoms of depressive or hypomanic syndromes. 6) Neurologic and clinical history was recorded. 7) A free conversation was established to identify possible current psychopathologic symptoms. If any of these items pointed to positive answers (symptom or treatment), the individual was excluded from the study, even when that made the volunteer feel disappointed.

One-way ANOVA was used for descriptive statistical analysis of the data, followed by Bonferroni correction to identify significant differences between variables. The Student $t$-test or the Mann-Whitney test was used for some of the variables. Some variables were compared according to crude score percentiles in the population (Raven test), and the other variables were compared according to their crude scores. Next, univariate linear regression was used for all scores before multiple linear regression analysis. Further statistical analyses were conducted using multiple linear regression, a stepwise linear analysis, adjusting for age, schooling and intelligence. The socioeconomic status of all patients and healthy controls was middle or lowmiddle class.

\section{RESULTS}

The study sample consisted of 111 subjects, 36 with schizophrenia, 28 with interictal SLPE, and 47 healthy controls. Table 1 shows that patients with epilepsy were significantly older than patients with schizophrenia and healthy controls and that their educational and intelligence levels were lower. Age and schooling of patients with schizophrenia did not differ significantly from those of healthy controls, but their intelligence level was lower. Levels of intelligence established according to the Raven test are different from those established by the IQ test, and the highest possible score is 50 points.

Multiple regression analysis of the results of the attention tests was used to compare both patient groups and healthy controls (Tables 2 and 3), as well as patient groups to each other (Table 4). All analyses were adjusted for age, schooling and intelligence level.

Table 2 shows that patients with schizophrenia had selective and sustained attention deficits compared to the healthy population. The number of omission errors was higher in the selective and sustained attention tasks. 
Table 1. Age, schooling and intelligence level of patients with schizophrenia, patients with interictal schizophrenia-like psychosis of epilepsy, and healthy controls.

\begin{tabular}{|c|c|c|c|c|}
\hline & $\mathrm{SCH}(\mathrm{N}=36)$ & SLPE $(N=28)$ & $\mathrm{HC}(\mathrm{N}=47)$ & ANOVA \\
\hline \multicolumn{5}{|l|}{ Age (years) } \\
\hline Mean \pm SD & $34.6 \pm 9.5$ & $39.9 \pm 8.8^{*}$ & $33.9 \pm 7.1$ & $F=4.989$ \\
\hline Median & 34 & 42 & 32 & $P=0.008$ \\
\hline Bonferroni & \multicolumn{4}{|c|}{ Epilepsy x controls: $6.078 ; P=0.009$} \\
\hline \multicolumn{5}{|c|}{ Schooling (years) } \\
\hline Mean \pm SD & $10.8 \pm 3.4$ & $9.2 \pm 3.6^{*}$ & $11.4 \pm 3.2$ & $F=3.887$ \\
\hline Median & 11 & 10 & 11 & $P=0.023$ \\
\hline Bonferroni & \multicolumn{4}{|c|}{ Epilepsy x controls: $-2.233 ; P=0.020$} \\
\hline \multicolumn{5}{|c|}{ Intelligence level (percentile) } \\
\hline Mean \pm SD & $26.06 \pm 23.31^{*}$ & $9.62 \pm 9.89^{*}$ & $39.89 \pm 24.03$ & $F=16.934$ \\
\hline Median & 20 & 5 & 35 & $P=0.001$ \\
\hline Bonferroni & $\begin{array}{l}\text { Schizophrenia } x \text { epilepsy } 12.58 \\
\text { Schizophrenia } x \text { controls }-5.077 \\
\text { Epilepsy } x \text { controls }-17.665 ; \mathrm{P}\end{array}$ & $\begin{array}{l}0.011 \\
0.016 \\
1\end{array}$ & & \\
\hline
\end{tabular}

$\mathrm{SCH}=$ schizophrenia; SLPE = schizophrenia-like psychosis of epilepsy; HC = healthy controls.

Table 2. Comparison of TAVIS-2R scores for patients with schizophrenia and controls adjusted for age, schooling and intelligence level.

\begin{tabular}{|c|c|c|c|c|c|c|c|c|c|}
\hline $\begin{array}{l}\text { Dependent } \\
\text { variable }\end{array}$ & $\begin{array}{c}\mathrm{RT}- \\
\text { selective }\end{array}$ & $\begin{array}{c}\mathrm{RT}- \\
\text { alternating }\end{array}$ & $\begin{array}{c}\text { RT- } \\
\text { sustained }\end{array}$ & $\begin{array}{c}\text { OE- } \\
\text { selective }\end{array}$ & $\begin{array}{c}\text { OE- } \\
\text { alternating }\end{array}$ & $\begin{array}{c}\text { OE- } \\
\text { sustained }\end{array}$ & $\begin{array}{c}\text { CE- } \\
\text { selective }\end{array}$ & $\begin{array}{c}\text { CE- } \\
\text { alternating }\end{array}$ & $\begin{array}{c}\text { CE- } \\
\text { sustained }\end{array}$ \\
\hline \multicolumn{10}{|l|}{ Age } \\
\hline $\mathrm{B}_{0}$ & 0.502 & 0.636 & 0.3 & 5.19 & 4.83 & 0.61 & 3.72 & 6.43 & 4.95 \\
\hline $\mathrm{B}_{1}$ & -0.01 & 0.02 & 0.04 & 1.98 & 1.09 & 0.36 & 0.36 & 2.67 & -5.21 \\
\hline SEM & 0.01 & 0.02 & 0.05 & 0.935 & 0.571 & 0.525 & 0.848 & 0.782 & 3.358 \\
\hline $\mathrm{P}$ & 0.26 & 0.44 & 0.462 & 0.038 & 0.061 & 0.491 & 0.669 & 0.001 & 0.126 \\
\hline \multicolumn{10}{|l|}{ Schooling } \\
\hline $\mathrm{B}_{2}$ & 0 & -0.05 & -0.06 & -2.51 & -1.39 & -0.39 & -0.89 & -0.74 & -0.03 \\
\hline SEM & 0.01 & 0.02 & 0.052 & 0.95 & 0.58 & 0.53 & 0.86 & 0.79 & 3.39 \\
\hline $\mathrm{P}$ & 0.96 & 0.01 & 0.277 & 0.01 & 0.019 & 0.464 & 0.303 & 0.353 & 0.993 \\
\hline \multicolumn{10}{|l|}{$I Q$} \\
\hline $\mathrm{B}_{3}$ & -0.02 & -0.01 & 0.08 & -1.74 & -2.18 & -0.74 & -1.54 & -3.3 & -3.62 \\
\hline SEM & 0.01 & 0.02 & 0.055 & 0.999 & 0.61 & 0.561 & 0.907 & 0.836 & 3.589 \\
\hline $\mathrm{P}$ & 0.19 & 0.73 & 0.14 & 0.086 & 0.001 & 0.194 & 0.094 & $<0.001$ & 0.317 \\
\hline \multicolumn{10}{|c|}{ Schizophrenia } \\
\hline $\mathrm{B}_{4}$ & 0 & 0.06 & 0.17 & 4.99 & 0.03 & 0.9 & 3.54 & -0.37 & 7.75 \\
\hline SEM & 0.01 & 0.02 & 0.053 & 0.961 & 0.587 & 0.54 & 0.872 & 0.804 & 3.453 \\
\hline$P$ & 0.85 & 0.01 & 0.002 & $<0.001$ & 0.953 & 0.034 & $<0.001$ & 0.649 & 0.028 \\
\hline
\end{tabular}

$B_{0}=$ regression coefficient for healthy controls; $B_{1}=$ regression coefficient for age; $B_{2}=$ regression coefficient for schooling; $B_{3}=$ regression coefficient for intelligence quotient (IQ); $B_{4}=$ regression coefficient for schizophrenia; $R T=$ reaction time; $O E=$ omission error; $\mathrm{CE}=$ commission error. Age: $<36$ years, $\geq 36$ years; schooling: $\leq 11$ years, $>11$ years; IQ: $<25 \%, \geq 25 \%$. 
Table 3. Comparison of TAVIS-2R scores for patients with epilepsy and controls adjusted for age, schooling and intelligence level.

\begin{tabular}{|c|c|c|c|c|c|c|c|c|c|}
\hline $\begin{array}{l}\text { Dependent } \\
\text { variable }\end{array}$ & $\begin{array}{c}\text { RT- } \\
\text { selective }\end{array}$ & $\begin{array}{c}\mathrm{RT}- \\
\text { alternating }\end{array}$ & $\begin{array}{c}\text { RT- } \\
\text { sustained }\end{array}$ & $\begin{array}{c}\text { OE- } \\
\text { selective }\end{array}$ & $\begin{array}{c}\text { OE- } \\
\text { alternating }\end{array}$ & $\begin{array}{c}\text { OE- } \\
\text { sustained }\end{array}$ & $\begin{array}{c}\text { CE- } \\
\text { selective }\end{array}$ & $\begin{array}{l}\text { CE- } \\
\text { alternating }\end{array}$ & $\begin{array}{c}\text { CE- } \\
\text { sustained }\end{array}$ \\
\hline \multicolumn{10}{|l|}{ Age } \\
\hline $\mathrm{B}_{0}$ & 0.48 & 0.64 & 0.4 & 4.99 & 5.28 & 0.05 & 2.97 & 6.83 & 0.49 \\
\hline $\mathrm{B}_{1}$ & -0.02 & -0.01 & -0.06 & 0.92 & 1.37 & -0.1 & 0.64 & 2.58 & 0.96 \\
\hline SEM & 0.01 & 0.03 & 0.04 & 1.23 & 1.01 & 0.04 & 1.21 & 1.35 & 1.05 \\
\hline $\mathrm{P}$ & 0.2 & 0.746 & 0.161 & 0.457 & 0.182 & 0.023 & 0.6 & 0.061 & 0.362 \\
\hline \multicolumn{10}{|l|}{ Schooling } \\
\hline $\mathrm{B}_{2}$ & 0 & -0.04 & -0.02 & -0.63 & -1.43 & -0.03 & -0.1 & -0.29 & 0.45 \\
\hline SEM & 0.01 & 0.03 & 0.04 & 1.23 & 1.01 & 0.04 & 1.21 & 1.35 & 1.04 \\
\hline $\mathrm{P}$ & 0.969 & 0.22 & 0.689 & 0.613 & 0.162 & 0.507 & 0.937 & 0.829 & 0.666 \\
\hline \multicolumn{10}{|l|}{ IQ } \\
\hline $\mathrm{B}_{3}$ & 0.01 & -0.01 & -0.03 & -2.07 & -2.87 & -0.01 & -1.13 & -4.01 & -0.84 \\
\hline SEM & 0.02 & 0.04 & 0.05 & 1.56 & 1.28 & 0.05 & 1.53 & 1.71 & 1.32 \\
\hline $\mathrm{P}$ & 0.582 & 0.886 & 0.6 & 0.189 & 0.029 & 0.832 & 0.463 & 0.022 & 0.53 \\
\hline \multicolumn{10}{|c|}{ Epileptic psychosis } \\
\hline $\mathrm{B}_{4}$ & -0.02 & 0.08 & 0.16 & 6.83 & 3.43 & 0.1 & 5.06 & 2.3 & 2.2 \\
\hline SEM & 0.02 & 0.04 & 0.06 & 1.67 & 1.37 & 0.06 & 1.64 & 1.83 & 1.42 \\
\hline$P$ & 0.319 & 0.078 & 0.008 & $<0.001$ & 0.015 & 0.076 & 0.003 & 0.063 & 0.126 \\
\hline
\end{tabular}

$B_{0}=$ regression coefficient for healthy controls; $B_{1}=$ regression coefficient for age; $B_{2}=$ regression coefficient for schooling; $B_{3}=$ regression coefficient for intelligence quotient (IQ); $B_{4}=$ regression coefficient for schizophrenia-like epileptic psychosis; $R T=$ reaction time; $\mathrm{OE}=$ omission error; $\mathrm{CE}=$ commission error. Age: $<36$ years, $\geq 36$ years; schooling: $\leq 11$ years, $>11$ years; IQ: $<25 \%, \geq 25 \%$.

Table 4. Comparison of TAVIS-2R scores for patients with schizophrenia and patients with epilepsy adjusted for age, schooling and intelligence level.

\begin{tabular}{|c|c|c|c|c|c|c|c|c|c|}
\hline $\begin{array}{l}\text { Dependent } \\
\text { variable }\end{array}$ & $\begin{array}{c}\text { RT- } \\
\text { selective }\end{array}$ & $\begin{array}{c}\mathrm{RT}- \\
\text { alternating }\end{array}$ & $\begin{array}{c}\text { RT- } \\
\text { sustained }\end{array}$ & $\begin{array}{c}\text { OE- } \\
\text { selective }\end{array}$ & $\begin{array}{l}\text { OE- } \\
\text { alternating }\end{array}$ & $\begin{array}{c}\text { OE- } \\
\text { sustained }\end{array}$ & $\begin{array}{c}\text { CE- } \\
\text { selective }\end{array}$ & $\begin{array}{l}\text { CE- } \\
\text { alternating }\end{array}$ & $\begin{array}{c}\text { CE- } \\
\text { sustained }\end{array}$ \\
\hline \multicolumn{10}{|l|}{ Age } \\
\hline $\mathrm{B}_{0}$ & 0.5 & 0.69 & 0.48 & 11.16 & 4.46 & 1.6 & 7.98 & 5.87 & 13.46 \\
\hline $\mathrm{B}_{1}$ & -0.03 & 0.01 & -0.02 & 1.36 & 1.13 & 0.49 & 0.06 & 2.22 & -5.1 \\
\hline SEM & 0.02 & 0.04 & 0.09 & 1.58 & 1.17 & 0.71 & 1.78 & 1.45 & 4.74 \\
\hline $\mathrm{P}$ & 0.09 & 0.807 & 0.797 & 0.393 & 0.341 & 0.494 & 0.973 & 0.132 & 0.287 \\
\hline \multicolumn{10}{|l|}{ Schooling } \\
\hline $\mathrm{B}_{2}$ & 0.02 & -0.11 & -0.1 & -2.97 & -2.32 & -0.59 & -1.38 & 0.29 & 0.63 \\
\hline SEM & 0.02 & 0.04 & 0.09 & 1.68 & 1.25 & 0.75 & 1.89 & 1.54 & 5.04 \\
\hline $\mathrm{P}$ & 0.26 & 0.016 & 0.275 & 0.083 & 0.069 & 0.441 & 0.47 & 0.85 & 0.901 \\
\hline \multicolumn{10}{|l|}{$I Q$} \\
\hline $\mathrm{B}_{3}$ & -0.02 & 0.04 & 0.13 & -3 & -0.74 & -1.25 & -2.49 & -3.18 & -5.79 \\
\hline SEM & 0.02 & 0.05 & 0.1 & 1.83 & 1.36 & 0.82 & 2.06 & 1.68 & 5.5 \\
\hline $\mathrm{P}$ & 0.381 & 0.394 & 0.2 & 0.107 & 0.587 & 0.135 & 0.233 & 0.064 & 0.297 \\
\hline \multicolumn{10}{|c|}{ Epileptic psychosis } \\
\hline $\mathrm{B}_{4}$ & -0.03 & 0.02 & 0.06 & 0.96 & 4.46 & -1.65 & 0.87 & 2.1 & -6.01 \\
\hline SEM & 0.02 & 0.04 & 0.09 & 1.74 & 1.3 & 0.78 & 1.96 & 1.6 & 5.24 \\
\hline $\mathrm{P}$ & 0.144 & 0.631 & 0.557 & 0.586 & 0.001 & 0.04 & 0.659 & 0.195 & 0.256 \\
\hline
\end{tabular}

$B_{0}=$ regression coefficient for healthy controls; $B_{1}=$ regression coefficient for age; $B_{2}=$ regression coefficient for schooling; $B_{3}=$ regression coefficient for intelligence quotient (IQ); $B_{4}=$ regression coefficient for schizophrenia-like epileptic psychosis; $R T=$ reaction time; $\mathrm{OE}=$ omission error; $\mathrm{CE}=$ commission error. Age: $<36$ years, $\geq 36$ years; schooling: $\leq 11$ years, $>11$ years; IQ: $<25 \%, \geq 25 \%$. 
Table 3 describes the comparison between patients with epilepsy and healthy controls. Patients with epilepsy had alternating and selective attention deficits, and omission errors were more frequent in the group of patients with epilepsy in the three evaluations. The number of commission errors was different in all but the sustained attention tasks.

The comparison of patients with epilepsy and patients with schizophrenia (Table 4) revealed that there was no statistically significant difference in the three measurements of reaction times or in the frequency of commission errors. A statistically significant difference was found for omission errors in the alternating and sustained attention tasks. Equivalent results were found for the two patient groups in the selective attention task: both groups had a greater number of omission and commission errors than healthy controls (Tables 2 and 3), with no significant difference between patients with schizophrenia and patients with epilepsy (Table 4).

The frequency of commission and omission errors made by patients with schizophrenia in the alternating attention task was not significantly different from those made by healthy controls (Table 2). Patients in the epilepsy group had a greater number of omission errors than healthy controls, whereas the difference in the number of commission errors was marginally significant $(P<0.06)$. The number of omission errors for the alternating attention was significantly greater in the epilepsy group than in the schizophrenia group (Table 4). For sustained attention, patients with schizophrenia made more omission and commission errors than healthy controls (Table 2). No statistically significant difference was found between patients with epilepsy and healthy controls in this task, although the difference in the frequency of omission errors bordered significance $(P<0.07)$.

Age at psychosis onset (mean: schizophrenia $=24.4$ (7.6); epilepsy $=28.7(11.3)$ ) and duration of psychosis (mean: schizophrenia $=10.2$ (7.3); epilepsy $=11.2(10.1)$ ) were similar in the two groups of patients. Among the 28 patients with epilepsy, the development of psychotic symptoms preceded the onset of seizures in only 2 patients: for 1 of them by 15 years, and for the other by 5 years. For all other patients in this group, epileptic seizures preceded psychotic symptoms by a mean number of 15 years. Mean number of hospitalizations was similar in the schizophrenia and epilepsy groups (1.6 (2.1) and 1.7 (3.4)). The analysis of distribution according to gender showed that $1 / 3$ of the patients were women in the schizophrenia group, $53.6 \%$ were women in the epilepsy group, and $38.3 \%$ in the control group. The association between gender and affective deficit was not evaluated in this study.
Some patients were receiving monotherapy, but most were also taking 2 or 3 psychotropic drugs; patients with schizophrenia were being treated with typical or atypical neuroleptic drugs, sometimes together with antianxiety medication. Patients with epileptic psychosis were taking one neuroleptic drug and one anticonvulsant drug, sometimes together with antianxiety medication. No patient was taking topiramate.

\section{DISCUSSION}

In the tests of selective attention, both patient groups made more omission and commission errors and had significantly worse results than healthy controls, with no difference between patient groups. Both groups showed deficits in selective attention and, therefore, are likely to face difficulties in adapting to their environment, as discussed in the introduction of this study. They may reach wrong conclusions and distort reality, or may have great difficulty in responding to external demands. In the alternating attention tests, patients in the epilepsy group made more omission errors than healthy controls, and the difference in the number of commission errors bordered significance $(P<0.06)$, perhaps due to a type II error. In this case, the difficulty in alternating the focus of attention may contribute to problems in interpersonal verbal interactions and may slow the rhythm of fluency when discussing a certain topic. In the sustained attention tasks, patients with schizophrenia had worse results than healthy controls both in numbers of omission and commission errors. As a result of constant changes of attentional focus, perhaps one of the factors responsible for poor persistence in activities, patients are unable to start and maintain an activity, or interpersonal verbal interactions, until completion of the activity. Patients with epilepsy showed a significantly greater number of omission errors in the alternating attention task but fewer omission errors in the sustained attention task than patients with schizophrenia.

The results were obtained after multiple regression analysis to rule out the effect of confounding factors: patients with epilepsy had a significantly greater mean age and fewer schooling years than those with schizophrenia or healthy controls. However, these differences were found in a clinically non-significant age bracket (mean age $=34$ to 39 years), and schooling was equivalent to secondary school.

The intelligence level of patients with epilepsy was significantly lower than that of patients with schizophrenia or healthy controls; patients with schizophrenia also had significantly lower intelligence scores than healthy controls. Low intelligence levels have been frequently described in samples of nonpsychotic patients with epilepsy 
(23). If patients with epilepsy but no associated psychosis tend to have a poorer intellectual performance, it is reasonable to expect that those with psychosis may have an even poorer performance. Chronic epilepsy is usually associated with less schooling.

Almost all patients were taking neuroleptic drugs, and patients with epilepsy and psychosis were also taking antiepileptic drugs. One of the limitations of our study was that we were not able to reduce individual medication doses to equivalent doses of one single standard psychotropic drug (chlorpromazine) because no data about the equivalence of atypical neuroleptic drugs are available, and no comparisons with antiepileptic drugs have been established. Moreover, these are the medications and doses necessary to make patients more balanced and clinically stable, and their cognitive profiles will reflect the use of such medication when they present to a cognitive rehabilitation team. No patient was taking a toxic dose of medication.

Another limitation of our study was the use of the TAVIS-2R test, which is still not a well-known and widely accepted method, but which has the necessary basic factors for good performance as a visual attention test: all symbols are familiar (24), and the test differentiates types of attention in each of its task more clearly than other validated and widely used tests. The problem of lack of validation was mitigated by the comparison of results with a control group, as proposed by Engelberts et al. (25).

The results reportd by Mellers et al. (14) are similar to our findings. These investigators studied the neuropsychological profiles of similar groups of patients compared with normal controls and nonpsychotic patients with epilepsy and found almost identical profiles: psychotic patients had attention deficits, whereas nonpsychotic patients with epilepsy did not. Other cognitive functions, such as intelligence level, memory and executive functions, did not differ between groups. Nathaniel-James et al. (22) compared similar groups and found that patients had almost the same cognitive performance profile. However, our results, which separated different types of attention, revealed differences between the diagnostic groups under study.

The sustained and alternating attention performances differed between the groups of patients with schizophrenia and with epilepsy and psychosis, whereas selective attention deficits were equally found in both clinical conditions. The comparison of qualitative clinical observations for both patient groups revealed that these quantitative results were coherent, that is, that patients with schizophrenia had difficulties in focusing attention, whereas those with epilepsy showed perseveration in the same focus.
Moreover, these results point to the fact that alternating attention is the opposite of sustained attention, that is, the greater the alternating attention, the lower the sustained attention, and vice versa.

Our findings suggest several new paths for this line of research: their correlation with positive or negative symptoms of psychoses or with the different types of epilepsy, investigation of psychological and neurophysiological phenomena in these conditions, and comparisons with other mental, cognitive or affective functions. They also indicate the need to validate the TAVIS-3R test (current version) for use with adults.

\section{ACKNOWLEDGMENTS}

The authors thank Kelsy Catherina Nema Areco, Universidade Federal de São Paulo, and Ronir Raggio Luiz and Antonio José Leal Costa, Universidade Federal do Rio de Janeiro, for assistance with the statistical analyses.

\section{REFERENCES}

1. Luria AR. Curso de psicologia geral. Atenção e memória. Rio de Janeiro: Civilização Brasileira; 1979.

2. Lezak MD. Basic concepts. In: Lezak MD (Editor), Neuropsychological assessment. 3rd edn. London: Oxford University Press; 1995. p 39.

3. Lent R. Mentes emocionais, mentes racionais: as bases neurais da emoção e da razão. In: Lent $\mathrm{R}$ (Editor), Cem bilhões de neurônios: conceitos fundamentais de neurociência. São Paulo: Atheneu; 2001. p 676.

4. Parasuraman R, Warm JS, Dember WN. Vigilance: taxonomy and utility. In: Mark LS, Warm JS, Huston RL (Editors), Ergonomics and human factors. New York: Springer Verlag; 1987. p 11-32.

5. Butler RW, Braff DL. Delusions: a review and integration. Schizophr Bull 1991; 17: 633-647.

6. Kaney S, Wolfenden M, Dewey ME, Bentall RP. Persecutory delusions and recall of threatening propositions. $\mathrm{Br} J$ Clin Psychol 1992; 31 (Part 1): 85-87.

7. Bentall RP, Kaney S, Bowen-Jones K. Persecutory delusions and recall of threat-related, depression-related and neutral words. Cognit Ther Res 1995; 19: 331-343.

8. Leafhead KM, Young AW, Szulecka TK. Delusions demand attention. Cognit Neuropsychiatry 1996; 1: 5-16.

9. Phillips ML, Senior C, David AS. Abnormal processing of ambiguity in paranoid schizophrenia: a visual scan path study. Psychol Med 2000; 30: 157-167.

10. Slater E, Beard AW, Glithero E. The schizophrenia-like psychoses of epilepsy. Br J Psychiatry 1963; 109: 95-150.

11. Reynolds EH. Epilepsy and schizophrenia: relationship and biochemistry. Lancet 1968; 1: 398-401.

12. Toone BK. The psychoses of epilepsy. J R Soc Med 1991; 84: 457-459.

13. Marchetti RL, Damasceno BP. Epilepsia: psicopatologia e comportamento. In: Guerreiro CAM, Guerreiro MM, Cendes F, Lopes-Cendes I (Editors), Epilepsias. São Paulo: Lemos Editorial; 2000. p 231.

14. Mellers JD, Toone BK, Lishman WA. A neuropsychological 
comparison of schizophrenia and schizophrenia-like psychosis of epilepsy. Psychol Med 2000; 30: 325-335.

15. Anonymous. American Psychiatric Association. Diagnostic and statistical manual of mental disorders. 4th edn. Washington: APA; 1994.

16. Commission on Classification and Terminology of the International League Against Epilepsy. Proposal for revised clinical and electroencephalographic classification of epileptic seizures. Epilepsia 1981; 22: 489-501.

17. Commission on Classification and Terminology of the International League Against Epilepsy. Proposal for revised classification of epilepsies and epileptic syndromes. Epilepsia 1989; 30: 389-399.

18. Pond DA. Psychiatric aspects of epilepsy. J Ind Med Prof 1957; 3: 1441-1451.

19. Duchesne M, Mattos P. Normalization of a computerized visual attention test (TAVIS). Arq Neuropsiquiatr 1997; 55: 62-69.

20. Raven JC. Testes das matrizes progressivas - escala geral, séries $A, B, C, D$ e $E$. Tradução e adaptação de Francisco Campos, revisão de Suzana Ezequiel da Cunha. Rio de Janeiro: Centro Editor de Psicologia Aplicada (CEPA); 1999.

21. Berman KF, Weinberger D. Functional localization in the brain in schizophrenia. In: Tasman A, Goldfinger SM (Editors), American psychiatric press review of psychiatry. Washington: American Psychiatric Press; 1991.

22. Nathaniel-James DA, Brown RG, Maier M, Mellers J, Toone $B$, Ron MA. Cognitive abnormalities in schizophrenia and schizophrenia-like psychosis of epilepsy. J Neuropsychiatry Clin Neurosci 2004; 16: 472-479.

23. Reynolds EH. Mental effects of antiepileptic medication: a review. Epilepsia 1983; 24 (Suppl 2): S85-S95.

24. Kanda PAM. Estudo da atenção na epilepsia parcial criptogênica. [Master's thesis]. São Paulo; EPM, UNIFESP; 1993.

25. Engelberts NH, Klein M, Ader HJ, Heimans JJ, Trenite DG, van der Ploeg HM. The effectiveness of cognitive rehabilitation for attention deficits in focal seizures: a randomized controlled study. Epilepsia 2002; 43: 587-595. 